\title{
The Research on Dimensions of Employer Attractiveness
}

\author{
Rong Liu, Yan Tao, and Mei-qing Han \\ Dalian University, College of Economic and Management, Dalian, 116622, Liaoning Province, China \\ liurong_dl@sina.com, taoyan_dl@sina.com
}

\begin{abstract}
On the base of previous study, we propose the dimension structure of employer attractiveness under the background of China. We prove that the dimensions of employer attractiveness mainly consist of the system of salary and development, the working environment and atmosphere, the recruitment process, the nature of work, and the strength of enterprise brand through questionnaire survey and empirical analysis. The findings suggest some ways to enhance the employer attractiveness.
\end{abstract}

Index Terms - Employer attractiveness, Dimension structure

\section{Introduction}

For the enterprise, one of the critical approaches to achieve long-term competitive excellence is to attract the best employees. Human resources become more significant and strategic, along with the rapid transmission of information and communication, and the employees transfer gets faster and easier, consequently, employees turnover rates continue to increase. Labour shortage concerns the enterprise and hinders the growth of enterprises. How to attract the best job applicants is a big challenge faced by business leaders. First, because job seekers compare the enterprise, their awareness of individual needs is growing, and they will choose the employers who agree their own personality characteristics. Second, more and more foreign companies settle in China, which will add to pressure on the domestic enterprise. Many companies are trying lots of ways to do the staff recruitment.

\section{Literature References}

\section{A. The Concept of Employer Attractiveness}

In 1996, Ambler and Barrow [1] first defined the employer attractiveness as: a combination of function, economic and psychological benefits in line with the employer, which is provided by the employer's employment practice. Then in 2005 Berthon, Ewing and Hah [2] put forward the concept "Employer Attractiveness", it is widely accepted, namely "the benefit that potential seekers expect to get from a specific set of work". It is a follow-up study on organization attractiveness or enterprise attractiveness after the proposed employer brand. The specific employer attractiveness is defined as how attractive organization to job seekers, the intensity of the desire job seekers work for organization. The employer includes individuals, enterprises and organizations; this study only focuses on the enterprise, the image representative of the workplace. The employer attractiveness not only has an influence on potential job seeker, but also the in-service staff. Accordingly, the employer attractiveness is defined as "the strength employer attracts job seeker and retains employees through all kinds of way and means, namely the external and internal attractiveness". The enterprise image or employer image is the outward manifestation of the employer attractiveness. External attractiveness is the strength that employer attracts job seekers to join the enterprise. The internal attractiveness is the strength that employer makes employees feel freewill to stay and contribute positively, through employees participate, perceive and experience life and work in the enterprise. The research object of this paper is mainly aimed job seeker, external attractiveness.

\section{B. Dimension Structure of Employer Attractiveness}

With regard to the research results on dimension structure of employer attractiveness, there is no uniform conclusion.

In 1996, Ambler and Barrow thought that dimension structure of employer attractiveness consists of functional value, economic value and psychological value by empirical analysis [3]. In 2002, Sutherland, Torricelli and Karg proposed the employer attractiveness mainly includes: career development opportunities, challenging work, salary, product innovation ability, rotation and differences[4]. In 2003 Lievens and Highhouse reached a conclusion via empirical analysis, when job seekers search for work, they pay more attention to functional value and symbolic value, functional value includes salary, promotion opportunities, the nature of work and the place of work; symbolic value includes sincerity, innovation, capability, reputation and robust [5]. In 2005, from the point of potential employees' expectation, Berthon, Ewing and Hah [6] designed employer attractiveness dimension scale which is composed of five dimensions and 25 items. The five dimensions are social value, economic value, interest value, development value and application value. In 2009, Xuejun Zhang took college students in the Guangzhou area as an example, got a research result of the five dimensions of employer attractiveness: development value, atmosphere value, environment value, reputation value and economic value [7]. Zhiqin Yang pointed out that in 2010 his empirical analysis result was employer attractiveness consists of credit value (leadership and system), basic value (organization strength), growth value (the prospect of organization), work value (the nature of job) and atmosphere value [8]. In 2012, Esra Alniacik, and Umit Alniacik [9] made a survey to 600 subjects in Turkey, and found six dimensions employer attractiveness: social value and market value, economic value, application value, cooperation value and work environment. Next year, Lei Zhang [10] led an empirical research in wellknown IT enterprise in Beijing; he found that four dimensions are composed of symbolic value, development value, economic value and social value. 


\section{Study design}

Many domestic and foreign scholars do the research of employer attractiveness, in general, their research has no unified results, connotation and dimensions they put forward are different, the research background, object and sample scholars choose are also not the same. Therefore, we study employer attractiveness by methods of literature review, questionnaire and interviews, to analyse elements of employer attractiveness, and make further efforts to identify dimensions of employer attractiveness in Chinese conditions.

\section{A. Variable Design}

In order to figure out the core elements of employer attractiveness, considering Chinese situations, we chose the variables that scholars used lots of time before as independent variable. Did the questionnaire, interview, pre-study and data analysis; ultimately determined variables. This paper kept Likert5 scale method on the questionnaire, divided items into 5 levels, namely, the answers were awfully unimportant, not important, average, important, and very important; these above levels were each given 1 points, 2 points, 3 points, 4 points and 5 points; a higher score indicates a potential job seekers think more often highly of the factors when they select a company.

\section{B. Data Acquisition}

This study took working staff, job seeker and students as research object, so that we could achieve the broad public awareness of employer attractiveness. Data was collected by actual and online distribution. The questionnaires went through two stages distribution. The first stage, before largescale questionnaires distribution, the initial step was pretesting to confirm the validity of scale. Item, reliability and validity analysis were conducted on the pre-survey data, and then according to the results, we deleted inappropriate items to make the final version of questionnaire. We mainly distributed questionnaire through hand-out and online in first stage, totally 100 questionnaire were issued, 97 questionnaires were available. The second stage, formal questionnaires were randomly distributed 320 copies; the response rate was $93.7 \%$.

\section{Data Analysis}

\section{A. Reliability and Validity Test}

We took the Cronbach's $\alpha$ coefficient and the CITC coefficient as the index to evaluate scale internal consistency. In the following table 1 we can see the SPSS17.0 analysis result, obviously to find that the Cronbach's coefficient is greater than 0.7 and the CICT coefficient values are greater than the standard 0.5. Meanwhile, the Cronbach's coefficient of corresponding dimension will decrease if we delete any one item in scale; this indicates the scale has good reliability; the questionnaire items are consistent with the whole questionnaire.
TABLE 1 Results of reliability analysis

\begin{tabular}{|c|c|c|c|c|}
\hline Dimensions & Items & CICT & $\begin{array}{l}\text { Cronbach's Alpha } \\
\text { of Items Deleted }\end{array}$ & $\begin{array}{c}\text { Cronbach's } \\
\text { Alpha }\end{array}$ \\
\hline \multirow{6}{*}{ gz1 } & $\mathrm{a} 8$ & .665 & .847 & \multirow{6}{*}{.869} \\
\hline & a9 & .653 & .849 & \\
\hline & a10 & .763 & .829 & \\
\hline & a11 & 699 & .841 & \\
\hline & a15 & .611 & .857 & \\
\hline & a16 & .617 & .856 & \\
\hline \multirow{4}{*}{ gz2 } & a4 & .652 & .762 & \multirow{4}{*}{.816} \\
\hline & a5 & .648 & .764 & \\
\hline & a6 & .655 & .766 & \\
\hline & a7 & .606 & .782 & \\
\hline \multirow{4}{*}{ gz3 } & a17 & .607 & .768 & \multirow{4}{*}{.808} \\
\hline & a18 & .618 & .764 & \\
\hline & a19 & .671 & .737 & \\
\hline & a20 & .610 & .768 & \\
\hline \multirow{3}{*}{ gz4 } & a12 & .681 & .821 & \multirow{3}{*}{.852} \\
\hline & a13 & .733 & .795 & \\
\hline & a14 & .749 & .788 & \\
\hline \multirow{3}{*}{ gz5 } & a1 & .467 & .726 & \multirow{3}{*}{.723} \\
\hline & a2 & .582 & .589 & \\
\hline & a3 & .593 & .582 & \\
\hline
\end{tabular}

Before the factor analysis on employer attractiveness, we first took validity analysis. The KMO test statistic value is 0.873 , Bartlett test value is 1737.402 , and $\mathrm{P}$ value is 0.000 , so the validity is significant, suitable for factor analysis as showed in table 2 .

TABLE 2 Results of KMO and Bartlett test

\begin{tabular}{|c|c|c|}
\hline \multicolumn{2}{|c|}{ Kaiser-Meyer-Olkin Measure of Sampling Adequacy } & .873 \\
\hline \multirow{3}{*}{ Bartlett Test of Sphericity } & Approximation Chi Square & 1737.402 \\
\cline { 2 - 3 } & $\mathrm{df}$ & 231 \\
\cline { 2 - 3 } & Sig. & .000 \\
\hline
\end{tabular}

\section{B. Exploration of Factor Analysis}

We analysed the 20 initial components of employer attractiveness to do factor analysis, and figured out the total variance table of employer attractiveness elements. Extract the factor which eigenvalue is greater than 1 , so the first 5 factor were picked out, the variance of first 5 factors account for $66.417 \%$ of the total, and can represent the majority of the independent variables. Therefore, this analyses effect is significant, from table 3 .

TABLE 3 Total Variance Explained

\begin{tabular}{|c|c|c|c|}
\hline Component & Total & \% of Variance & Cumulative \% \\
\hline 1 & 3.866 & 19.329 & 19.329 \\
\hline 2 & 2.670 & 13.352 & 32.681 \\
\hline 3 & 2.479 & 12.395 & 45.076 \\
\hline 4 & 2.335 & 11.675 & 56.752 \\
\hline 5 & 1.933 & 9.666 & 66.417 \\
\hline
\end{tabular}


We analysed the initial components of employer attractiveness to do factor analysis. Table 4 shows the max variance gets rotated and transformed. From the table, following result can be seen, the factor loading value of each item is greater than 0.4 , the phenomenon of cross loadings does exist, and the structure of 5 factors is very clear.

TABLE 4 Component transformation matrix

\begin{tabular}{|c|c|c|c|c|c|}
\hline \multirow{2}{*}{ Items } & \multicolumn{5}{|c|}{ Component } \\
\hline & 1 & 2 & 3 & 4 & 5 \\
\hline $\mathrm{a} 10$ & .879 & & & & .303 \\
\hline $\mathrm{a} 8$ & .762 & & & & \\
\hline $\mathrm{a} 9$ & .756 & & & & \\
\hline $\mathrm{a} 16$ & .692 & & & & \\
\hline $\mathrm{a} 11$ & .641 & & & & \\
\hline $\mathrm{a} 15$ & .623 & & & & \\
\hline $\mathrm{a} 7$ & & .787 & & & \\
\hline $\mathrm{a} 6$ & & .767 & & & \\
\hline $\mathrm{a} 5$ & .351 & .760 & & & \\
\hline $\mathrm{a} 4$ & .340 & .631 & & & \\
\hline $\mathrm{a} 19$ & & & .853 & & \\
\hline $\mathrm{a} 20$ & & & .797 & & \\
\hline $\mathrm{a} 18$ & & & .690 & .356 & \\
\hline $\mathrm{a} 17$ & .353 & & .609 & & \\
\hline $\mathrm{a} 12$ & & & & .809 & .374 \\
\hline $\mathrm{a} 14$ & & .340 & & .791 & \\
\hline $\mathrm{a} 13$ & & & & .765 & \\
\hline $\mathrm{a} 2$ & & & & & .867 \\
\hline $\mathrm{a} 3$ & & & & & .793 \\
\hline $\mathrm{a} 1$ & .367 & & & & .541 \\
\hline
\end{tabular}

The convergence rate of the rotation is deduced after sixth iteration.

\section{Confirmatory Factor Analysis}

Confirmatory factor analysis is to further test the conceptive structure, in order to confirm the accuracy of conceptive dimensions. We used Amos17.0 analysis software to do the confirmatory factor analysis of employer attractiveness dimensions, put our findings in Table 5.

The results show that: value of $\chi^{2}$ is 673.60 , degrees of freedom is 160 , so $\chi 2 / \mathrm{df}$ is 4.21 , which belong the standard range of 2 to 5; value of AGFI is 0.783 , close to the standard value of 0.8 . The fitting parameters GFI, NFI, CFI, and IFI are $0.835,0.803,0.893$, and 0.896 , one by one. They all close to the standard value of 0.9 ; the RMSEA and RMR values were $0.078,0.0493$, both in line with the standard requirements. This indicates that the model of confirmatory factor is fitting with data. In figure 1, it is obvious to find out the model of statistical results.

TABLE 5 the results of CFA analysis

\begin{tabular}{|c|c|c|c|c|c|c|c|c|}
\hline $\begin{array}{c}\text { Fitting } \\
\text { Parameters }\end{array}$ & $\chi 2 / \mathrm{df}$ & GFI & AGFI & IFI & NFI & CFI & RMSEA & RMR \\
\hline Standard & $<5$ & $>0.9$ & $>0.8$ & $>0.9$ & $>0.9$ & $>0.9$ & $<0.08$ & $<0.05$ \\
\hline Model & 4.21 & 0.835 & 0.783 & 0.896 & 0.803 & 0.893 & 0.078 & 0.049 \\
\hline
\end{tabular}

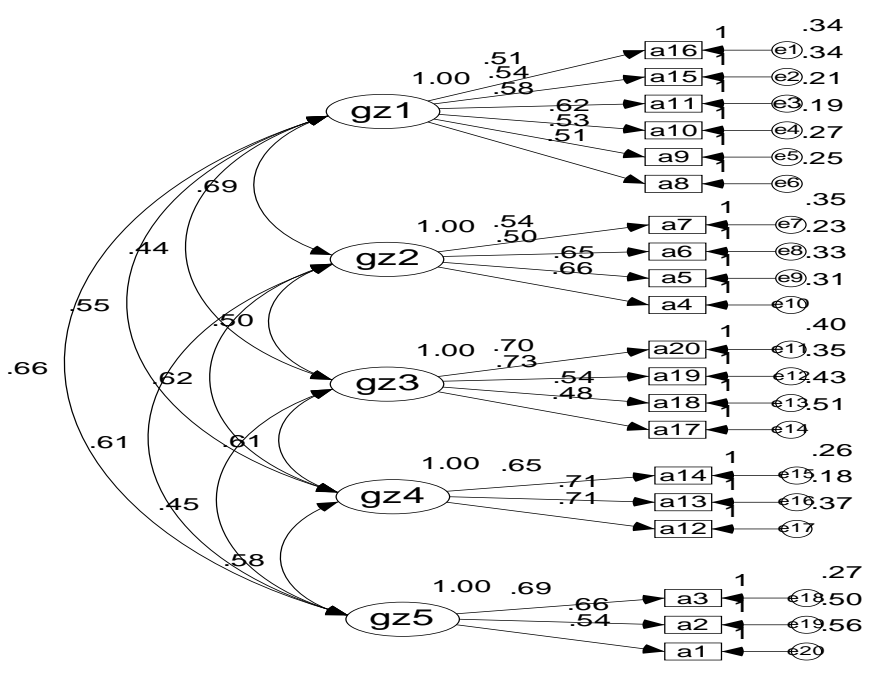

Fig.1 the results of CFA analysis

\section{The Discussion about Research Results}

Employer attractiveness consists of five dimensions, according to the analysis results of the data. Each dimension is defined and explained as follows.

Dimensions 1, the system of salary and development (gz1), includes excellent salary and welfare management system, payment system equal with my work performance, higher wages, generous welfare benefits, the enterprise can provide smooth career promotion channels, the enterprise can provide a stable job, and I am ready to balance work and life.

Dimension 2, the work environment and atmosphere (gz2), includes the awareness entrepreneurs want to make the enterprise bigger and stronger, employee engagement, strive to improve themselves, good cooperation relationship among departments and I can identify the corporate culture and values.

Dimension 3, the recruitment process (gz3), includes I recognize the manners in recruitment, I think the process of recruitment is very fair, advertisement can catch eye easily, and enterprise website is good design and easy to find what we need.

Dimension 4, the nature of work (gz4), includes work match with my profession, I can play my professional expertise, and the enterprises can provide a challenging job for me.

Dimension 5, the strength of enterprise brand (gz5), includes the high reputation in the talent market, big size, good market position, the enterprise in the industry with high market position.

From the factor analysis results, we can find out the dimensions of employer attractiveness are consistent with previous research. In the past research, salary and welfare, career development, working environment and atmosphere, the nature of work and the enterprise's strength are brought in sharp focus. However, we propose the recruitment process; it makes this paper different from previous studies, so the enterprises should invest their time and energy to the recruitment. 


\section{Summary and Suggestions}

This paper demonstrates employer attractiveness is composed of five dimensions. The variance contribution rate of $66.417 \%$ has good representation. The dimensions of employer attractiveness are almost consistent with previous research; only different point is that we propose the recruitment process, this new result tell us people's selfawareness is enhancing. In the recruitment process, the manners and words of recruiters, recruitment feedback, and advert for a job all have an influence on job seeker. The research is intended to study the broad sense of the employer attractiveness, so the more and lager investigation scope, more representative, this article only received 300 valid questionnaires, and the questionnaires are mostly distributed in the coastal areas from Liaoning to Zhejiang province, so the sample is short of representation. In addition, different individual, different recognition and evaluation, such as age, gender, education, occupation and other will affect the evaluation on employer attractiveness, but this study does not analyse the influence the individual characteristics have on employer attractiveness evaluation. In future research, we can expand the range of samples, and study the influence of individual characteristics.

According to this study, we hereby put forward the following suggestions to enhance the employer attractiveness.

\section{A. To Establish the Excellent System of Salary and Development}

One of the main dimensions of employer attractiveness is the system of salary and development, it is the key point to attract and retain talent. The salary is the basic guarantee of the staff's life; a good salary can make employees put more energy and time into work. In addition, healthy and fast development is another pursuit of the staff, in the development; employees get salary increase, prove their ability, and get company recognition. All of these boost the confidence and sense of pride of employees, and inspire their work passionate.

\section{B. To Provide the Harmonious Work Environment and Atmosphere}

The work environment and atmosphere will affect the employee's satisfaction, emotion and enthusiasm. A good work environment will make employees feel comfortable, and work atmosphere will affect the work ways, methods and efficiency. So now many large companies are advocating simple interpersonal relationship in enterprises, career development depends on personal ability, not on the relationship, therefore employees will pay entire attention to work, not dealing with interpersonal relationships. The enterprises should create a work atmosphere with mutual help, support and care, treat employees friendly, and make employees establish equal, respect, trust interpersonal relationship.

\section{To Improve the Recruitment Process}

The employees know the enterprise start from the recruitment process, through the recruitment information, recruitment forms, the recruiter's performance and attitude, the feedback, and the welcome ceremony. So more and more companies attach importance to the recruitment, make elaborate efforts, and invest a lot of money and labour to improve recruitment work.

\section{To Make Work Rich and Challenging}

Research shows that one of the most important factors is the nature of work. The enterprises need to provide work that meets the demands of staff, have to carry out work design. Challenging work, job enrichment, job rotation, and job enlargement are effective method. To expand the content of job requires more knowledge and skills, so work become challenging, this will increase employee job satisfaction, improve the quality of work and interest.

\section{E. To Build the Enterprise Brand}

The enterprises should learn from marketing theory, build the corporate image to keep a brand effect on employees and job seekers, that is the establishment of employer brand. To build the enterprise brand, it is an advantage not only for inservice employees, but also for potential job seeker and those who quit job. The enterprise build employer brand must consider internal and external brand, and the organic integration of both.

\section{References}

[1] Ambler T, Barrow S .The employer brand. Journal of Brand Management.1996, 4:185-206.

[2] Berthon P., Ewing M., HahL.L. Captivating company: dimensions of attractiveness in employer branding. International Journal of Advertising.2005, 23:151-172.

[3] Tim Ambler, Simon Barrow. The employer brand. Journal of Brand Management.1996 (3):185-206.

[4] Sutherland, MM. Torricelli, DG, and Karg, RF. Employer-of-choice branding for knowledge workers. South African Journal of Business Management.2002, 33(4):13-20.

[5] Filip Lievevs, Scott Highhouse. The relation of instrumental and symbolic attributes to a company's attractiveness as an employer. Personnel Psychology.2003 (1):75-102.

[6] Berthon P., Ewing M., Hah L.L. Captivating company: dimensions of attractiveness in employer branding. International Journal of Advertising.2005, 23(2):151-172.

[7] Xuejun Zhang, The research on dimension of employer attractiveness and related study - university graduates in Guangzhou area as an example. Guangzhou: Jinan University, 2009.

[8] Zhiqin Yang. The dimension measure of organization attractiveness and the enlightenment on Enterprise talent strategy. Science and technology management. 2010(6):170-172.

[9] Esra Alniacik, Umit Alniacik. Identifying dimensions of attractiveness in employer branding: effects of age, gender, and current employment status. Procedia Social and Behavioural Sciences. 2012(58): 13361343.

[10] Lei Zhang. The effect factors of employer attractiveness of IT company in Beijing. Beijing: Beijing Forestry University, 2013. 